NBER WORKING PAPER SERIES

\title{
ADJUSTMENT IN PROPERTY SPACE MARKETS: ESTIMATES FROM THE STOCKHOLM OFFICE MARKET
}

\author{
Peter Englund \\ Åke Gunnelin \\ Patric H. Hendershott \\ Bo Söderberg \\ Working Paper 11345 \\ http://www.nber.org/papers/w11345
}

\section{NATIONAL BUREAU OF ECONOMIC RESEARCH 1050 Massachusetts Avenue Cambridge, MA 02138}

May 2005

The views expressed herein are those of the author(s) and do not necessarily reflect the views of the National Bureau of Economic Research.

(C)2005 by Peter Englund, Ake Gunnelin, Patric H. Hendershott, and Bo Soderberg. All rights reserved. Short sections of text, not to exceed two paragraphs, may be quoted without explicit permission provided that full credit, including $(\mathrm{C}$ notice, is given to the source. 
Adjustment in Property Space Markets: Estimates from the Stockholm Office Market

Peter Englund, Åke Gunnelin, Patric H. Hendershott, and Bo Söderberg

NBER Working Paper No. 11345

May 2005, Revised July 2006

JEL No. R1

\section{ABSTRACT}

We analyze the joint dynamics of property space markets using an error-correction model, where rent and vacancies adjust to deviations from equilibrium rent and vacancies. The analysis is based on a new lease rent series for the Stockholm office rental market for the time-period $1977-2002$ constructed by standard hedonic methods applied to a data-set of some 2,400 individual leases. Simulations illustrate the separate roles of rent and vacancy rate movements in the adjustment process. We calculate the natural vacancy rate assuming a trending equilibrium. Property markets may be slow to adjust because tenants are constrained by long-term leases and may be slow to adjust to current rents for other reasons. This gives rise to "hidden vacancies" (the difference between space occupancy and demand at the current lease rate). Using our market rent series and the lease-length distribution, we estimate a time series on the average rent on existing leases. We find that most of the variation in hidden vacancies is explained by the difference between demand at current and average rent.

Peter Englund

Department of Finance

Stockholm School of Economics

P.O. Box 650

11383 Stockholm, Sweden

peter.englund@hhs.se

Åke Gunnelin

Department of Infrastructure

Royal Institute of Technology

10044 Stockholm, Sweden

ake.gunnelin@infra.kth.se
Patric H. Hendershott

Centre for Property Research

University of Aberdeen Business School

Aberdeen AB24 3QY

Scotland, UK

and NBER

phh3939@arvig.net

Bo Söderberg

Department of Business Administration

University of Gavle

80176 Gavle

Sweden

bsg@hig.se 


\title{
Adjustment in Property Space Markets: Estimates from the Stockholm CBD Office Market
}

\author{
Peter Englund \\ Department of Finance, Stockholm School of Economics, P.O. Box 6501, 11383 Stockholm, Sweden. \\ Phone: +46 87369154 Email: Peter.Englund@hhs.se
}

Åke Gunnelin

Department of Infrastructure, Royal Institute of Technology, 10044 Stockholm, Sweden. Phone: +46 879089 82. Email: ake.gunnelin@infra.kth.se

Patric H. Hendershott

Centre for Property Research, University of Aberdeen Business School, Aberdeen AB24 3QY, Scotland, UK. Email: phh3939@arvig.net US phone: 218-963-1393

Bo Söderberg

Department of Business Administration and Economics, University of Gävle, 80176 Gävle, Sweden. Phone: +46 266481 93. Email: bsg@ hig.se

April 2, 2006

\begin{abstract}
Markets for property space adjust only gradually because tenants are constrained by long-term leases and landlords and tenants face transactions and information costs. Not only do rents adjust slowly, but space occupancy may differ from demand at current rent, giving rise to "hidden vacancies". We estimate the joint dynamics of office rents and vacancies using an error-correction model using a new lease rent series for Stockholm offices 1977-2002 estimated on 2,500 leases. It takes 5-10 years for the market to adjust to a shock. In a model simulation of a positive employment shock open vacancies fall from the natural level of 7 percent to below 4 percent, while hidden vacancies increase by about as much. Most of the variation in hidden vacancies over time is explained by the difference between demand at current and average rent on existing leases, which we calculate using data on contract lease length.
\end{abstract}

Descriptors: rent, vacancy rate, natural vacancies, hidden vacancies.

JEL classification: R0, R1 


\section{Introduction}

If all lease contracts were renegotiated every time period and there were no search and transaction costs and other market frictions, then there would be no vacancies. Rents would continuously adjust to equate demand and supply. Commercial property space markets are more complex than this. Rents are the outcome of a search process, where landlords and prospective tenants look for a good match in terms of rent and characteristics of the premises. Leases are typically long term, and tenants are unable to adjust their space consumption continuously. As a result vacancies are a central feature of property markets. Because demand and supply for individual units are continuously subject to idiosyncratic shocks, some vacancies would exist even if there were no aggregate shocks to the market. Market shocks cause market vacancies to deviate temporarily from their normal ("natural") level during a transition period until equilibrium is restored.

A simplified characterization of market equilibrium in a world of one period leases and zero transaction costs is that demand equals supply minus natural vacancies, where the natural vacancy rate depends on the frequency of shocks and the properties of the matching process between units and tenants. Outside equilibrium, rents adjust gradually toward equilibrium, reflecting slow dissemination of information and strategic pricing decisions by landlords. Vacancies adjust so that occupied space (supply minus vacancies) equals demand at the current rent. In such a world the deviation of the vacancy rate from its natural level would simply be a mirror image of the deviation of rent from its equilibrium level.

In practice, rents and vacancies are not simple mirror images of each other but play separate roles in the adjustment process. A major reason is multi-period lease contracts, which lock tenants into rents signed in earlier periods. Furthermore, space consumption may be locked in due to moving costs even in a world with one-period contracts. We can draw a distinction between long run (or normal) demand, depending on the rent on newly-written leases only, and short run demand (defined to equal observed space occupancy), which depends on other factors, in particular historic lease terms. This is somewhat analogous to the rigidities in labor markets with long-term wage contracts restricting current employment as analyzed in the macro literature. To illustrate, if most space were leased under long-term contracts at earlier low rental rates, then current short-run demand would be higher than if all space were being leased at today's high current rents. We refer to this temporary (until leases roll over) higher space usage as "hidden vacancies".

We develop and use new data from the Stockholm office market to better understand the roles of rent and vacancies in the adjustment process in commercial space markets. The Stockholm market is particularly interesting because the typical lease length increased from only one year to three years during 
the 30 year period covered by our data. The key model input we create is a series of real rents for new leases holding physical characteristics and lease length and other contract features constant. This rent index is computed from estimates of a hedonic rent equation based on 2485 individual office leases written during the 1972-2002 period. Based on this rent measure and data on vacancies, the supply of office space and office-sector employment, we estimate an error-correction model of rents, vacancies and supply.

In long-run equilibrium, employment, supply and real rent in Stockholm all grow at constant rates and vacancies equal the natural rate. Defining natural vacancies in a trending equilibrium (which is necessary given the clear upward trend in real rent) - rather than the standard definition based on a stationary equilibrium where rent remains constant - makes an important difference. We estimate the natural vacancy rate for Stockholm to be around 7 percent, a third less than that estimated under the standard stationary equilibrium definition.

A key feature of our analysis is the explicit analysis of the dynamics of vacancies, as well as rents. Each adjusts to the deviation of both variables from their equilibrium levels and to concurrent changes in employment and supply. Our estimates indicate that about a third of a gap between current and equilibrium rents and a fourth of a gap between vacancies and natural vacancies are closed within a year. Moreover, adjustment of each variable is significantly related to the disequilibrium gap in the other. In addition, we account for asymmetries caused by the lower zero bound on the vacancy rate. More specifically, while large positive or negative demand (employment) shocks likely cause sharp vacancy changes when the vacancy rate is high, when it is low, a large positive shock cannot lower vacancies significantly.

We illustrate the adjustment process, especially the role of hidden vacancies, with a simulated shock to employment, the exogenous variable in the model. The adjustment towards the new equilibrium is cyclical with rents overshooting the new equilibrium by 25 percent after five years. During much of the adjustment process rents are above equilibrium while vacancies remain below the natural rate, indicating the presence of hidden vacancies.

Section 2 explains our estimate of a constant-quality real rent index, and Section 3 provides background developments in the Stockholm office market since the 1970s, including a presentation of the data used. In Section 4 we turn to a discussion of the determination of equilibrium real rent, providing both a brief literature review and model estimates. Section 5 derives two alternative estimates of hidden vacancies in Stockholm during the last quarter century. Time series regressions explaining the rent, vacancy and supply adjustment processes are then reported in Section 6. Section 7 concludes. 


\section{Estimates of Constant-Quality Lease Rates}

The key data input into the current study is an index series of real rent per square meter of constantquality, newly-leased office space in the Stockholm CBD. We create this from a sample of 2485 individual office leases written between 1972 and 2002 using the hedonic methodology employed, e.g., by Wheaton and Torto (1994) and Webb and Fisher (1996). The offices are owned by a set of institutional investors, including insurance companies, pension funds, and specialized property holding companies. For the most recent years, 1998 - 2002, we draw on a database maintained by SFI/IPD Swedish Property Index based on information from 13 major owners with holdings covering about 30 percent of total CBD office space. For the years prior to 1998 we have collected leases from the archives of two of the most important owners in this group with holdings of close to 40 percent of all SFI/IPD offices in the Stockholm CBD.

The index is meant to apply to standard office leases with normal lease terms. We have deleted non-standard observations based on the following criteria: leases for a shorter term than nine months (which have notably different renewal rights); leases for unusually large or small premises (below 25 square meters and above 2500 square meters), and observations with apparent data coding errors in any variable used in the index estimation. The remaining lease observations are used for the estimation of the constant quality rent index.

Table 1 presents annual data on the numbers of leases and properties, the average lease length, and the fraction of the leases that were newly written. The number of leases in the data base varies considerably over time, ranging from less than 40 per year between 1973 and 1976 to close to 200 between 1999 and 2001. The main reason for the high numbers of observations in the last few years is the addition of many more property owners from 1998 when we have access to the SFI/IPD data: the number of new leases triples from 1998 to 1999. But there are large variations from year to year for other reasons. Part of the variation reflects the different phases of the property cycle. The increase in number of leases during the market boom in the late 1980s (especially 1989) coincides with increased new supply, whereas the low numbers in the early 1990s reflects a surge in vacancy rates. Some of the variation could also be due to missing observations. For the earlier period we have accessed all leases still remaining in the archives of the two property owners. But because we do not have access to records on the total stock of rental premises of these owners, we have no way of checking for missing observations. Our general impression, however, is that the files of leases that we have examined are complete and that all new contracts were added chronologically as the old ones expired.

The number of lease observations is also affected by the length of leases signed in previous 
years; the shorter are leases, the more frequently an office appears in the data base. The distribution of the length of newly signed leases is directly observed in the data. We use these data to calculate the fraction of all leases expiring. These calculations are based on the assumption that we observe a random sample of all contracts and that the total stock of offices remains constant. To start, we assume that all leases in the stock in 1972 had a remaining maturity of one year. The distribution of maturities in the stock for subsequent years is calculated recursively, deriving the fraction of expiring leases from the observed distribution of lease lengths in preceding years. For each year the observed length distribution for new leases is applied to the fraction of leases expiring, i.e., one-year leases written in the previous year, two-year leases written two years ago, etc. Based on this we compute the fraction of leases expiring in year $t$ as the fraction of leases with one year to go in $t-1$. The increase in average lease length from just over one year in the early 1970s to over three years in the late 1980s reduces the fraction of newly signed leases in our data base. This fraction dropped from $3 / 4$ in the 1970 s to $1 / 3$ in recent years.

Our data include key information about the lease: contract rent, starting and closing date, and size of the premises. Furthermore we know if the lease is the result of the renegotiation with an old tenant. Because the data come from the same set of landlords, individual offices undoubtedly appear several times in the data set. Unfortunately the data do not allow us to identify individual offices, but we can identify the building in which the office is located. In the hedonic regression we use an indicator variable for each building in the data set to capture quality differences across offices.

The data also indicate the presence of special clauses like inflation indexation, heating clauses, graduated rent clauses, and rent concessions. For the period 1972-1991 there is quantitative information about rent concessions and various forms of graduated rents allowing us to transform contract rents into effective rents along the lines of Hendershott (1996) and Webb and Fisher (1996). Such concessions were present in a small minority of all contracts. For later years we only have indicators of the presence of special contract clauses and are constrained to capture the average impact on rent through dummy variables. The extent to which this may bias our index estimates depends on the variability of rent concessions over time. It is likely that rent-free periods and the like were more common during the market crisis of the early 1990s than during other periods. If the average size of concessions was the same all years this should not lead to biased index estimates. It is more likely, however, that the concessions also were larger than usual during these years, in which case our index estimates for this period are upward biased. Exact variable definitions along with sample statistics are stated in Table 2.

Using these data we estimate a hedonic rent equation for newly-written leases with time represented by year dummies. We take special care with the lease-length term. In studies using basically the same data for a shorter time period, Gunnelin and Söderberg (2003) and Englund et al. (2004) found 
that the relation between rent and lease length often is non-linear. Short leases tend to be more expensive due to transaction costs, and the impact of term on rent varies over time reflecting expectations of future rent levels. To allow for a time-varying non-linear relation we interact lease-length and lease-length squared with year dummies. The constant quality rent index is calculated as the rent for a standard contract by evaluating the estimated equation for each year holding all explanatory variables constant at their sample average values.

The estimated equation is presented in Table 3. It has a high explanatory power $\left(\right.$ adjusted $\mathrm{R}^{2}=$ 0.962) largely due to the inclusion of property dummies. Square meter rent is seen to increase with size for smaller offices, reaching a maximum at 1250 sq. meters, and to decrease for larger offices. The rent level is 5 per cent lower for a renegotiated contract than for a contract with a new tenant. According to the estimated coefficients inflation indexation and being charged separately for heating (HEAT_2) both tend to raise the rent, which may appear counterintuitive. We interpret these results as reflecting unmeasured quality characteristics; such heating and indexation clauses are more common for highquality offices.

The resulting index series is plotted in Figure 1. It exhibits strong cycles in real rent in the late 1980s and early 1990s and again in the late 1990s and early 2000s around an upward trend. Having estimated the real rent level for new leases and the distribution of leases over maturities, we can calculate the average rent in the stock in a given year by assigning the new lease rent in each year to the portion of the stock existing in the given year that was leased up in that year and summing across all lease up years. This time series for average real rent is also plotted in Figure 1. The differences between the new and average series were relatively small during the 1970s and 1980s, when leases were short and rents were relatively stable. However, when leases lengthened and real rents plunged and then rebounded in the 1990s, the percentage difference fell to a minimum of -25 percent in 1993 and then rose to a maximum of 26 percent in 2000 .

\section{The Stockholm Office Market during Three Decades}

The development of the Stockholm office market since the early 1970s is illustrated in Figure 2, which plots the data series used in our empirical analysis. A general control of residential and commercial rents was introduced in Sweden during the Second World War and remained in force with little change until the early 1970s. Residential rents remain regulated even today, although details of the system have been modified. Consequently, residential rents still fail to reflect site rents, particularly in central locations in Stockholm. For office rents a four-year deregulation process started in 1972. This involved the right for tenants to a gradual adjustment towards market rent between 1972 and 1976. The deregulation process 
was evaluated after the adjustment period. In effect there was a threat of reinstalling some form of control. It is reasonable to believe that this restrained landlords for several years and put some constraints on rent setting throughout the 1970s.

The top panel plots our rent index of newly leased office space together with a measure of vacancies. The vacancy rate series refers to office space in the inner city of Stockholm and is derived from estimates by property consultants. For the period before 1989 we have obtained vacancy estimates directly from a leading consulting company, the Catella Property Group. For later years they come from the property consultant NewSec AB (accessed from the data base of the Swedish Central Bank; www.riksbanken.se). The geographical area for which the vacancy data are measured is not defined exactly by the suppliers, but appears to be somewhat wider than the CBD for which we have rental data.

Real rents developed smoothly during the transition years of deregulation with modest changes between 1972 and 1977. Following years are characterized by two pronounced rent cycles: thirteen years of boom between 1977 and 1990 with real rents increasing by 10.5 percent per year, a sharp bust between 1990 and 1994 with rents falling by 13.8 percent per year bringing rent back to its 1981 level, a long recovery between 1994 and 2001 with rent increases averaging 8.9 percent per year, and finally the onset of a new recession after 2001. Vacancies mirror rents fairly closely. They remained below 5 percent throughout the 1970s and 80s and started to shoot up only in 1990, the year when real rent peaked. During the crisis vacancies reached unprecedented levels, exceeding 20 percent in 1993. But five years later the vacancy rate was again below five percent and remained there until 2002.

The lower panel of Figure 2 depicts the drivers of this development, the supply and demand for office space. Supply is measured by the number of square meters of office space in the inner city of Stockholm. The series is constructed starting from an inventory of the stock of office space estimated in 1968 by Statistics Stockholm. For later years we have added data on net additions of new office space, measured in square meters, using publicly available data on building permits and demolitions from Statistics Stockholm. To proxy the demand for office space we use office sector employment in the city of Stockholm, a somewhat wider area than that of the other series. ${ }^{1}$

These series show strong and sustained trends. Supply increases every single year, at an average rate of 1.3 percent over the whole period. The growth in office employment is even stronger (on average 3.4 percent per year from 1972 to 2002), but with large short-term fluctuations related to the business cycle. Note especially the contrast between the sharp 3.9 percent annual decrease during the 1989-93 crisis and the sustained rises in earlier years, by 4.4 percent annually between 1977 and 1989, and in later

\footnotetext{
${ }^{1}$ From 1985 these data are taken directly from the Labor Force Surveys (Arbetskraftsundersökningen, AKU). For earlier years they were estimated based on census data (for 1970, 1975, 1980 and 1985), interpolated using data on
} 
years, by 5.9 between 1993 and 2002. The first period of strong growth occurred when the vacancy rate was already quite low, i.e., demand growth could not lower vacancies noticeably. The supply changes were much smaller and smoother with little variation over time: increases of 1.5 percent annually during the 1977-1989 period, 1.4 percent during the 1989-1993 crisis, and 0.5 percent during the 1993-2002 recovery. The combined impact of these demand and supply data is consistent with the actual real rent development: sharp rises in the 1980s and again in the latter part of the 1990s, with a plunge in between. Overall, employment increased by 2.5 times, while supply increased by only 0.5 times. The result was a tripling of real rent. ${ }^{2}$

\section{Equilibrium Real Rent}

There is a long empirical literature dealing with the adjustment process in space markets, beginning with Smith (1974); see Hendershott, MacGregor and Tse (2002) for a recent survey. Much of the early literature focused on the role of vacancies as a driver of rent adjustment. A common formulation expressed the rate of change of real rent as a function of the deviation of vacancies from a natural vacancy rate, implicitly defined as the vacancy rate consistent with constant real rents. While this formulation gave important insights, it had some shortcomings as a representation of the dynamics of space markets. In particular, it left the equilibrium rent level out of the picture; this rent was neither determined by the model nor did it play any role in the adjustment process. More recent modeling of rent dynamics has started from an explicit model of equilibrium rent.

The first authors to specify equilibrium rent were Wheaton and Torto (1994) and Wheaton et al (1997). In these papers a model with two equations is described. The first is a pseudo space-demand equation:

$$
O S_{t}=\alpha_{0}+\left(\alpha_{1}+\alpha_{2} R_{t}\right) E_{t}
$$

where $O S$ represents demand assuming one period leases and no adjustment costs and $E$ is a demand indicator (financial services employment for the office sector). The other equation relates equilibrium rent to past vacancies and net absorption, $A B$, defined as the change in occupied space $O S$ :

the total population.

${ }^{2}$ It is noteworthy that a real rent series supplied by the property consultant Newsec and the Swedish Riksbank (www.riksbank.se), which covers all of Stockholm city rather than just the CBD, does not have an equally strong upward trend as our series (the increase from 1981 to 2002 is only 50 percent compared to 130 percent in our data). 


$$
R_{t}=\mu_{0}-\mu_{1} v_{t-1}+\mu_{2}\left(A B_{t-1} / O S_{t-1}\right)
$$

This equation is motivated by search models - e.g., Arnott (1989) and Wheaton (1990) - that imply an equilibrium rent between the reservation rents of landlords and tenants. Reservation rents cannot be observed but are assumed to depend on the number of vacancies and the gross flow of new tenants searching for office space. While this makes sense in theory, there is a big slip in going from theory to the empirical specification (2). Net absorption does not equal the number of tenants searching. Gross absorption is the number of successful matches - tenants not only searching but actually finding something - and net absorption (which deducts new space) is even further away from theory.

The model (1) - (2) can be solved for steady-state values $R^{*}$ and $v^{*}$ where absorption is zero and occupied space equals demand:

$$
\begin{aligned}
& O S^{*}=S\left(1-v^{*}\right)=\alpha_{0}+\left(\alpha_{1}+\alpha_{2} R^{*}\right) E \\
& R^{*}=\mu_{0}-\mu_{1} v^{*}
\end{aligned}
$$

The first equation is standard: rent is set by demand equalling supply at the natural vacancy rate. The second equation indicates the combinations of rent and vacancy levels that are consistent with occupied space being constant. Solving the two equations gives equilibrium rent and vacancies as functions of supply and employment. An increase in supply decreases rents and increases vacancies, and, conversely, an increase in employment increases rent and decreases vacancies. The second equation is decidedly non-standard. In virtually the entire literature $v^{*}$ is exogenously determined by structural factors in the market, such as the frequencies of shocks and the properties of the matching process between units and tenants (including lease length). ${ }^{3}$ The equilibrium levels of supply and employment are not directly relevant to this process.

More recently, Hendershott (1996) and Hendershott, Matysiak and Lizieri (1999) took another tack, calculating $R^{*}$ outside the space market model as the user cost of capital (or replacement cost rent) - the product of replacement cost and the sum of the real discount factor, the depreciation rate and the operating expense ratio (all divided by $1-v^{*}$ ). While straightforward in principle, this approach has two potentially serious problems. The first is the determination of the discount factor (i.e., the real return requirement); treating it as a constant certainly introduces error. Second, changes in the discount factor

Real rent series we have seen for Australian, UK, and US cities do not exhibit upward trends.

${ }^{3}$ The estimates of local vacancy rates reported by Voith and Crone (1988) and Grenadier (1995a) indicate a large 
may at least partly get capitalized into land price, which in central locations is a dominant part of replacement cost. Because equilibrium land price (and hence replacement cost) is not directly observable, the impact of changes in the real return requirement on equilibrium rent would then be unknown, and with full capitalization there would be no impact.

Hendershott, MacGregor and Tse (2002) avoid these problems by utilizing a long-run equilibrium model of the space market to estimate the equilibrium rent. In this paper we adopt their approach, specifying the long-run demand for office space as a log-linear function of real rent and employment,

$$
\ln D(R, E)=\lambda_{0}+\lambda_{R} \ln R+\lambda_{E} \ln E
$$

where the price elasticity $\lambda_{R}$ is negative and the 'income' elasticity $\lambda_{E}$ is positive. In a search market context $R$ should be thought of as the average rent on new contracts. Actual space occupancy may deviate from the demand function because of transaction costs and because tenants are locked into old contracts.

In long-run equilibrium, where the vacancy rate equals the natural rate, all leases carry the current rent, and all adjustments have been made, demand will equal total supply minus equilibrium vacancies:

$$
O S^{*}=D\left(R^{*}, E\right)=\left(1-v^{*}\right) S
$$

Taking the logarithm of (4), substituting from (3) with $R$ replaced by $R^{*}$, and solving for $\ln R^{*}$ then gives

$$
\ln R^{*}=\gamma_{S}\left[\ln \left(1-v^{*}\right)-\lambda_{0}\right]+\gamma_{E} \ln E+\gamma_{S} \ln S
$$

where the parameters of the demand equation (the price and income elasticities) can be retrieved as $\lambda_{R}=1 / \gamma_{S}$ and $\lambda_{E}=-\gamma_{E} / \gamma_{S}$. Note that if the elasticity of demand with respect to employment is unity $\left(\gamma_{S}=-\gamma_{E}\right.$ and $\left.\lambda_{E}=1\right)$, then real rent is proportional to employment per unit space.

Equations like (5), with $v *$ treated as a constant determined by structural characteristics of the variation in natural vacancy rates across regions. 
local office market, have been widely estimated on European data for all property types. ${ }^{4}$ Demand drivers used in the literature vary depending on the property type under consideration, and these variables typically carry high $t$-ratios. In contrast, the supply term has had little explanatory power, probably because decent quality supply data are rarely available.

In estimating an equation like (5), the dynamic properties of the variables are crucial. Figure 2 certainly suggests that our Stockholm data may be non-stationary. In the appendix we report tests for stationarity around deterministic linear trends. For $\ln R$ and $\ln S$ neither the augmented Dickey-Fuller nor the Phillips-Perron test comes close to rejecting non-stationarity, while the two tests give conflicting indications for $\ln E$ and $v$ with Dickey-Fuller rejecting non-stationarity at the 6 percent level. Based on these results we have chosen to treat $\ln R, \ln S$, and $\ln E$ as random walks with drifts, i.e., as being driven by the combination of a deterministic and a stochastic trend. The vacancy rate, on the other hand is taken to be non-stationary, consistent with the notion of a natural vacancy rate.

The equilibrium condition (5) links these non-stationary variables to each other, suggesting the possibility that the deviations from equilibrium are stationary, i.e., that the series are cointegrated. Johansen trace tests indicate the presence of one or two cointegrating relations between $\ln R, \ln S$ and $\ln E$. Based on our simple model with one equilibrium condition we choose to estimate a model with one cointegrating vector.

The estimated coefficients of the cointegrating equation turn out to be quite sensitive to the choice of starting date before 1977, but change little for later starting dates. We take this as an indication that rent deregulation was effectively completed only in 1977 and base the econometric analysis on data starting in that year. Another reason for discarding the first few years of data is that the number of leases in our data base is quite small during some of these years but effectively doubles between 1976 and 1977, thereby increasing the accuracy of the rent index estimates only from that year. Results based on 19772002 data are reported in Table 4. The coefficients on the supply and employment variables are virtually identical in absolute value; it is clearly employees per unit space that is driving real rent. The price elasticity (unity divided by the $\ln S$ coefficient) is -0.55 and the income elasticity (the $\ln E$ coefficient divided by the $\ln S$ coefficient) is 1.04. For London data, corresponding estimates are -0.24 and 0.92 (Hendershott, Matysiak and Lizieri, 1999). That is, the income elasticities are similar, but the Stockholm price elasticity is about double.

Figure 3 depicts the estimated equilibrium real rent $\left(R^{*}\right)$ and the observed real rent on new leases $(R)$. Actual rent tracks equilibrium reasonably closely through 1985, but is far above equilibrium

\footnotetext{
${ }^{4}$ Early studies include Gardiner and Henneberry (1988 and 1991) and Silver and Goode (1990); see Hendershott, MacGregor and White (2002) for a survey and panel estimation of UK regional real rents.
} 
between 1986 and 1990, jumping about twice the increase in equilibrium during the late 1980s. After being back on track for about five years, actual rent is below equilibrium during the 1997-2000 period, lagging the sharp increase in equilibrium rent during the second half of the 1990s. In 2002 the actual rent drops sharply below equilibrium. This difference between $R$ and $R^{*}$, i.e., the residual from this cointegration equation, is employed in the short-run estimation.

\section{Hidden Vacancies}

At any instant, there are several reasons why occupied space may deviate from demand at the current rent level, the primary one being that many tenants are locked into old contracts and, in the absence of default, can only adjust their space consumption as their contracts expire. Further, space consumption can typically only be adjusted through moves that entail costs for both tenants and landlords. Hence, even with short contracts some tenants will be locked into offices demanded based on historical rent levels. Thus current space consumption reflects past demand, which depends on past rental rates and past expectations of space needs over the course of the contract, rather than on the current rent. That is, even in the absence of new shocks to the space market, vacancies may rise of fall in the future.

We represent this difference between demand as a function of current rent and actual space occupancy by introducing the concept of hidden vacancies (that may be either positive or negative). The hidden vacancy rate, $v h$, is implicitly defined by the market clearing condition:

$$
D\left(R_{t}, E_{t}\right) \equiv\left(1-v_{t}-v h_{t}\right) S_{t}
$$

(recall that $\mathrm{D}(\mathrm{R}, \mathrm{E})$ is the long-run or "fully adjusted" demand). Alternatively, and algebraically more convenient, we may define a variable $X$ as the ratio of occupied space, (1-v)S, to space demanded at current rents, $(1-v-v h) S$. That is, $X=(1-v) /(1-v-v h))$ and $\ln X \approx v h$. Then we can write

$$
X \cdot D\left(R_{t}, E_{t}\right) \equiv\left(1-v_{t}\right) S_{t}
$$

Hidden vacancies cannot be observed directly but they may be inferred based on estimates of the demand equation and the equilibrium rent and vacancy rate. A broad measure of hidden vacancies, $X_{b}$, is obtained as follows. First, we substitute the equilibrium demand equation (3), for $\mathrm{R}=\mathrm{R}^{*}$, into the $\log$ of equation (4) and the actual demand equation (3) into the log of equation (6'), obtaining 


$$
\begin{aligned}
& \lambda_{0}+\lambda_{R} \ln R^{*}+\lambda_{E} \ln E=\ln \left(1-v^{*}\right)+\ln S \\
& \lambda_{0}+\lambda_{R} \ln R+\lambda_{E} \ln E+\ln X_{b}=\ln (1-v)+\ln S .
\end{aligned}
$$

We then deduct the left and right hand sides of the first equation from these sides in the second and solve

$$
\ln X_{b}=\lambda_{R}\left(\ln R^{*}-\ln R\right)+\ln (1-v)-\ln \left(1-v^{*}\right) .
$$

Hidden vacancies are positive if current rents are below equilibrium and/or vacancies are below the natural vacancy rate.

If multi-period contracts were the only reason for occupied space deviating from demand at the current rent level, then an alternative, narrow, measure of hidden vacancies, $X_{n}$, would be the ratio of demand at the average rent level across all leases to demand at the current rent for new contracts. Taking the log of this ratio and expressing these demands in the form of equation (3) gives

$$
\ln X_{n}=\lambda_{R}(\ln R a v g-\ln R),
$$

where Ravg is the average lease rate across all existing contracts.

Subtracting the left and right sides of (8) from the corresponding sides of (7) yields

$$
\ln X_{b}=\ln X_{n}+\lambda_{R}\left(\ln R^{*}-\ln R a v g\right)+\ln (1-v)-\ln \left(1-v^{*}\right) .
$$

Different movements in the broad and narrow measures indicate the extent to which the hidden vacancy rate reflects factors other than the existence of long-term contracts.

Our long run rent equation gives an estimate of $\lambda_{R}\left(1 / \gamma_{S}=-0.55\right)$ and a time series on $\ln R^{*}-\ln R$ (= $\varepsilon$, the residual). Based on a $\mathrm{v}^{*}$ estimate of 0.071 (see section 5.2 below), our two estimates of the hidden vacancy rate are

$$
\begin{aligned}
& \ln X_{b}=0.55\left(\ln R-\ln R^{*}\right)+\ln (1-v)-(1-0.071) \\
& \ln X_{n}=0.55(\ln R-\ln \text { Ravg })
\end{aligned}
$$


Figure 4 plots these two measures. They are clearly positively correlated, as equation (9) suggests they would be, but with pronounced differences over extended periods. More specifically, the broad measure is higher from 1981 to 1992 and lower for all years thereafter.

Throughout the 1980s the narrow measure is constantly close to zero. With contract lengths remaining quite short (two years on average) the difference between the rent on new leases and the average rent was rather small. Even when rents accelerated in 1986, narrowly defined hidden vacancies only increased to just above 7 percent. The broader measure on the other hand increased much further reaching almost 17 percent in 1986 and 1987 and 18 percent in 1990, indicating that tenants were slow to adapt their space occupancy downwards even as contracts were renewed at above-equilibrium rent levels.

In the depth of the crisis in the early 1990s, the hidden vacancy rate turned strongly negative according to both measures, around -15 percent in 1993. The sharp drop in rents between 1990 and 1993 was the result of a rather modest decrease in equilibrium rent and an alignment between market and equilibrium rents. With the rent close to its equilibrium level, negative hidden vacancies according to the broad measure were simply the other side of open vacancies being above the natural rate. In 1993 this under consumption of space was almost fully accounted for by the difference between current and average rent, i.e., the broad and narrow measures only differed by 1.5 percent. The market recovery during the latter part of the 1990s led to an increase in hidden vacancies. The narrow measure peaked at almost 13 percent in 2000. Interestingly the broad measure remained negative throughout the 1990s and only became marginally positive in 2000 and 2001. High vacancy rates until 1997 held the broad hidden vacancy rate series below the narrow, and then a growing gap between equilibrium and average rents kept the broad measure below the narrow measure through 2002. Apparently tenants were reluctant to increase space consumption despite below-equilibrium rent levels. This could be due to transaction costs in switching from smaller to larger premises as old contracts expired.

\section{Rent, Open and Hidden Vacancies, and Supply in the Adjustment Process}

A general model of the adjustment process allows rents on new leases, $R$, to adjust not only to vacancies but also to the gap between the equilibrium and actual rent levels and to the change in the determinants of equilibrium rent. ${ }^{5}$ This is in contrast to much of the earlier literature that modeled the

\footnotetext{
${ }^{5}$ As to why the level of $R^{*}$ is relevant to $R$, consider the following. At any point in time there is a series of $(R, v)$ values that would clear the market; a higher $R$ is associated with a higher $v$. The landlord's task is to attempt to maximize property value by setting $R$ appropriately. Say that $R>R^{*}$, triggering new construction. The expected future increase in space will lead landlords to expect a lower future $R$. With that expectation, it would be strategic to lower $R$ (and $v$ ) a bit now, rather than waiting to eliminate vacancies when $R$ is substantially lower. On the other hand with $R<R^{*}$ there will be less construction and a higher expected $R$ in the future, etc.
} 
change in rent as a function of the vacancy rate only. Thus we specify the adjustment equation in loglinear terms as

$$
\Delta \ln R_{t}=\ln R_{t}-\ln R_{t-1}=\beta_{v}\left(v_{t-1}^{*}-v_{t-1}\right)+\beta_{R}\left(\ln R_{t-1}^{*}-\ln R_{t-1}\right)+\beta_{R^{*}} \Delta \ln R_{t}^{*},
$$

where asterisks denote equilibrium values. The adjustment coefficients are $\beta_{v}$ for the vacancy rate gap, $\beta$ ${ }_{R}$ for the rent gap and $\beta_{R^{*}}$ for the equilibrium change. If $v^{*}$ is treated as a constant and one assumes a stationary equilibrium, as researchers have done, $v^{*}$ can be calculated as the estimated constant term in this equation divided by $\beta_{v}$, the coefficient on the lagged vacancy rate. On the other hand, if a trending equilibrium exists (if $R^{*}$ has a trend), then the intercept will reflect the growth rate in $R^{*}$ and the $v^{*}$ calculation will have to reflect it. We calculate $v^{*}$ both ways below.

\subsection{Specification}

Substituting the lagged error from estimation of the long-run equation (5) for $\ln R^{*}-\ln R$ in equation (10) and including changes in employment and supply to reflect concurrent changes in equilibrium rent, we have a standard error-correction equation with the addition of lagged vacancies (implicitly the gap between lagged vacancies and the constant natural vacancy rate) as an extra disequilibrium indicator.

$$
\Delta \ln R_{t}=\beta_{0}-\beta_{v} v_{t-1}-\beta_{R} \varepsilon_{R, t-1}+\beta_{E} \Delta \ln E_{t}-\beta_{S} \Delta \ln S_{t}
$$

Here $\varepsilon_{R}\left(=\ln R-\ln R^{*}\right)$ is the residual from the cointegrating long-run regression. The model is driven by one exogenous variable, employment, which we specify as an autoregressive process in differences. The immediate responses to employment and supply shocks are given by the coefficients $\beta_{E}$ and $\beta_{S}$.

For the dynamics of vacancies we posit an analogue to (10'):

$$
\Delta v_{t}=\eta_{0}-\eta_{v} v_{t-1}+\eta_{R} \varepsilon_{R, t-1}-\eta_{E} \Delta \ln E_{t}+\eta_{S} \Delta \ln S_{t}
$$

where $\eta_{R}$ and $\eta_{v}$ are the responses of the vacancy rate to the initial rent and vacancy rate gaps, and $\eta_{E}$ and $\eta_{S}$ indicate the impact of concurrent shocks to employment and supply.

Existing office market models do not explain $v$, but rather explain $D$ and then solve the identity: 


$$
D\left(R_{t}, E_{t}\right) \equiv\left(1-v_{t}\right) S_{t} \equiv O S_{t}
$$

for $v$. Note that this equation is incorrect insofar as it ignores hidden vacancies, the $X$ in equation (6'). If there were never any hidden vacancies $(X=1)$, then rents and vacancies would be mirror images of each other. $R$ above equilibrium would imply $v$ above equilibrium and vice versa, and there would be no point in specifying separate rates of adjustment to the rent and vacancy gaps.

Wheaton et. al. (1997) estimate the current change in occupied space:

$$
A B=d\left(O S_{t}^{*}-O S_{t-1}\right) \quad \text { or } \quad O S_{t}=d O S_{t}^{*}+(1-d) O S_{t-1}
$$

where $d$ can be interpreted as "the fraction of firms adjusting their actual consumption to long run demand" (p. 80), i.e., as our fraction of new contracts (column 4 of Table 1). Hendershott, Matysiak and Lizieri (1999) explain demand similarly, although they estimate it in two steps: first a long run demand equation like (1) and then an error-correction absorption equation. In either case, the adjustment equation effectively assumes that lease life and the fraction of newly built space are constant over time. The severity of real estate cycles belies the latter, and lease life has increased significantly over time in Stockholm. Given the wide variation in the fraction of new contracts in our data, we do not estimate a model where this fraction is assumed constant, but instead estimate the vacancy adjustment equation.

Turning to the determinants of supply, traditional investment theory suggests that new construction is triggered when property values are sufficiently high relative to construction costs, i.e., a Tobin's q argument. Real-option theory qualifies the trigger rule and points out the role of uncertainty in the timing of new supply. ${ }^{6}$ Hence, in order to model supply one would want time series of property prices, construction costs and a measure of uncertainty. Unfortunately, reliable time series for these variables are not available for the Stockholm market. We take a short-cut by positing that changes in supply, in analogy with rents and vacancies, depend on lagged values of $R-R^{*}$ (positively) and $v-v^{*}$ (negatively). One way of justifying this is to note that if the real discount factor were constant over time and expectations of future time paths of $R$ and $v$ were systematically related to differences between current and equilibrium values, then there would be a close connection between current rents and vacancies on the one hand and property prices on the other.

\footnotetext{
${ }^{6}$ See Grenadier $(1995 b, 1996)$ for the application of real option theory to investment and vacancy determination in real estate markets.
} 
Given that it takes time to build, the time lag from the disequilibrium indicators to the increase in supply may be longer than the corresponding one-year lag in the rent and vacancy adjustment equations. By the same argument it does not seem reasonable to expect that contemporaneous changes in $E$ affect current supply. Thus, we specify the following supply model:

$$
\Delta \ln S_{t}=\psi_{0}-\psi_{v} v_{-}+\psi_{\varepsilon} \varepsilon_{R-}
$$

Here the notation $v_{\text {- }}$ and $\varepsilon_{R_{-}}$indicates an unspecified time lag from when investment decisions are made to when new office space is put on the market. We let the data determine the time lag.

\subsection{Estimation}

In estimating the three-equation system (10'), (11) and (14), we account for the possibility that the error terms may be correlated by using the method of seemingly unrelated regressions (SUR). We generally allow for lagged one- and two-period changes in the dependent variable in order to eliminate residual autocorrelation, but these matter only for the rent equation. In the rent and vacancy equations the disequilibrium variables are both lagged one period in keeping with the standard error-correction formulation. In the supply equation the corresponding terms only get significant when lagged three periods, an indication of the time lag from decision to completion of new construction.

Estimation results for the basic model are presented in the first column of Table 5. The errorcorrection mechanisms work as anticipated; the rent and vacancy rate gap variables have correctly signed and statistically significant effects in both the rent and vacancy equations. As noted, the vacancy and rent disequilibrium variables are significant in the supply equation only when lagged three years. We take this as an indication of time-to-build effects; only information available a few years back in time affects today's addition to supply. In the rent equation, the negative coefficient on lagged rent changes indicates an element of cyclicality in the adjustment process. To obtain a more plausible lag structure, we have restricted the coefficients on the one- and two-year lagged rent changes to take the same value. ${ }^{7}$

Consider as an example of the adjustment process an initial position with rent being ten percent above equilibrium and the vacancy rate equaling the natural rate. Over the next year this will cause the rent level to go down by 3.8 percent, closing over a third of the gap. But it will also have cross effects leading the vacancy rate to increase by 0.6 percentage points and new construction to increase by 2.4

\footnotetext{
7 Unrestricted estimation yields a small and insignificant lag one coefficient (-0.20) but a large and significant lag two coefficient (-0.44). The difference between the coefficients is not significant, however. The P-value for a Wald test is 0.2 . Constraining the lagged rent coefficients to be equal has a negligible impact on the other coefficients.
} 
percent three years later. The increase in vacancies will in turn slow the adjustment of rent in following periods, and the increase in building will modify the rent increase needed to restore equilibrium. Rents may approach the new equilibrium smoothly or cyclically depending on details of the parameter estimates. The interplay between rent and vacancy adjustment will be further illustrated in then next subsection with a simulation.

Contemporaneous changes to employment and supply are included in both the rent and vacancy rate equations in a symmetric fashion so as to allow for an immediate impact of concurrent supply and demand shocks. The coefficients for the employment disturbance are economically and statistically significant in both equations. The rent elasticity is close to unity, and a one percent increase in employment leads to an instantaneous drop in the vacancy rate by a third of a percentage point. The supply coefficient is zero in the vacancy equation, but in the rent equation it is slightly larger in absolute value than the employment coefficient (although insignificantly different from zero). These coefficients are also opposite in sign and insignificantly different in magnitude in the long run rent equation. The coefficients are roughly 0.7 as large as in the long run equation, indicating that rent adjusts by 70 percent of the concurrent change in equilibrium rent.

The estimated supply elasticity is very low. Current rents 20 percent above equilibrium will induce a half percent addition to the stock of office space per year with a three-year lag. Vacancies have slightly stronger effects. A vacancy rate two points above the natural rate will induce a 1.5 percent stock increase. These small effects may reflect a lack of available new building space and restrictive planning controls on high rise construction, as suggested by the strong upward trend in real rents.

In earlier research on the space market, computation of the natural vacancy has assumed a stationary equilibrium; the natural rate has been calculated as the negative of the ratio of the constant term in a rent equation to the vacancy rate coefficient. In our model such a computation can be based on any of the three equations and, not surprisingly, varies with the equation used: 9.5 percent based on the rent equation, 12.5 percent based on the vacancy equation, and 19.2 percent based on the supply equation. When we estimate the model constraining the implied natural vacancy rates to be equal, we obtain 11.6 percent. However, inspection of the vacancy plot in Figure 2 suggests that a double digit natural vacancy rate is implausibly high. Observed vacancies exceeded ten percent in only four of the 31 years and remained under five percent for nearly all of the first two decades.

While a stationary equilibrium is plausible when real rents have no trend, this is not the case for the Stockholm CBD (see Figure 2). Instead of a stationary equilibrium, we posit a trending equilibrium and define the natural vacancy rate as the constant rate that is consistent with all variables following steady-state trends and the rent level being in equilibrium. The system is driven by the exogenous trend 
in employment. Solving the employment equation for $\Delta \ln E_{t}=\Delta \ln E_{t-1}$ yields a trend of 3.3 percent. Inserting this into the other three equations while setting $\Delta v_{t}=\varepsilon_{R, t-i}=0$ and $v_{t-i}=v^{*}$, yields an estimate of $v^{*}$ along with estimates of the equilibrium trends $(\Delta l n)$ in $S$ and $R$. The results are presented in the bottom panel of Table 5. Not surprisingly, the trend values solved are close to the mean growth rates of $R, E$, and $S$ over the estimation period. The combination of a strong trend in employment (3.3 percent per annum) and a modest supply increase ( 0.9 percent) gives rise to a very strong trend in rent ( 4.5 percent). ${ }^{8}$ This trending equilibrium yields the far more plausible natural rate of 7.1 percent.

\subsection{Shock adjustment and hidden vacancies}

The role of hidden vacancies is best illustrated by a simulation of the impact over time on $R, v$, and $v h$ of an employment shock. We start from an equilibrium situation with $R, E$, and $S$ all growing at their deterministic trend rates and vacancies being at their natural rate. Figure 5 illustrates the impact of a 10 percent permanent increase in the level of employment relative to its trend growth rate. The top panel shows the development over time of equilibrium and current rents after the shock relative to their levels in the absence of the employment shock. The result is an immediate 21 percent increase in equilibrium rent followed by a slow adjustment downwards as supply is adjusted (with a three year lag). The increase in supply is very small even in the long-run, which explains why the rent path remains 18 percent above its original steady-state growth path. Current rent rises by a little over half of the equilibrium increase in the first year and most of the rest in the second. It continues to rise for the next three years, however, overshooting by about 5 percentage points after five years ( 25 percent of the equilibrium increase). This unwinds over the next eight years.

The impact on vacancies, both open and hidden, is illustrated in the lower panel of Figure 5. About half of the expansion in space demand is initially met by a three-and-a-half percentage point decline in the vacancy rate. This is slowly reversed over the next decade. By the fourth year, vacancy is still below equilibrium despite rent being above equilibrium. This may seem implausible: with rent above equilibrium we would think demand would be insufficient and thus vacancy would be above equilibrium. This paradox is resolved by hidden vacancies, the bottom line in the graph, which amount to around 3.5 percent of space. While the rent on new leases is above equilibrium, some old leases carry below equilibrium rents and thus space occupancy is higher than the new lease rate indicates and the recorded vacancy rate is about two percentage points below equilibrium. Adding hidden and open vacancies, the "total" vacancy rate exceeds the natural level of 7 percent throughout the rest of the adjustment process, as expected.

\footnotetext{
${ }^{8}$ Note that these trends are also approximately consistent with the cointegrating equation.
} 


\section{Asymmetric Responses}

A potential problem with the vacancy and rent equations is that the vacancy rate cannot be negative. While sharp declines in employment or increases in supply can raise the vacancy rate sharply, changes in the opposite direction are limited in their ability to lower vacancies, particularly when the vacancy rate is low. Given that Stockholm vacancies never exceeded 4.4 percent throughout the 1970s and 1980s (see Figure 2), negative adjustments to the vacancy rate were limited during much of our estimation period. Thus, the sharp employment growth from the late 1970s to the end of the 1980s had little scope to lower the vacancy rate. In contrast, the rapid growth in employment in the middle 1990s could sharply lower the vacancy rate. Moreover, the plunge in employment during 1990-93 could easily have caused a steep increase in vacancies.

To allow for such an asymmetry, we partition $\Delta \ln E_{t}$ into positive and negative changes (we cannot partition $\Delta \ln S_{t}$ because it does not take on negative values). Further, to allow the impact of employment increases to vary with the level of the vacancy rate, we include both the change itself and the change multiplied by the lagged vacancy rate as regressors. This is another reason for preferring direct explanation of the vacancy rate rather than solving for it residually using an absorption equation that does not allow for asymmetric responses. Responses to the vacancy rate and rent gaps are less of a problem. Only when the lagged vacancy rate is high (above the natural rate) does it induce downward movement in vacancies, and at that point there is much scope for declines. And only when rent is below equilibrium is there pressure for vacancy rate declines. As it turns out, our estimates of the equilibrium rent (see Figure 3) indicate that large gaps between the equilibrium and actual rent level did not occur until the late 1980s.

A similar problem exists with the supply estimation. One would expect the magnitude of the supply response to $q$ values above and below unity to be significantly different; high $q$ s will trigger an investment boom, while low $q$ s would simply cause postponement of replacement investment. We account for the fact that negative adjustments are limited to depreciation by allowing the coefficients to differ depending on the signs of $v-v^{*}$ and $\varepsilon_{R}$.

The second column of Table 5 provides estimates allowing for asymmetric responses in all three equations. This substantially increases the equation fits. Relative to the basic model the adjusted $R^{2}$ rises from 0.58 to 0.67 (rent), from 0.58 to 0.77 (vacancy rate), and from 0.32 to 0.43 (supply). The implied natural vacancy rate and trend growth rates are essentially the same as in the basic model. ${ }^{9}$ When the

\footnotetext{
${ }^{9}$ The natural vacancy rate and trends are calculated as the unconditional expected values of $\mathrm{d} \ln R, \mathrm{~d} \ln S$ and $v$. This involves the covariances between $v$ and $\operatorname{d} \ln E(+)$ and the expected values of $\operatorname{d} \ln E$ conditional on $\mathrm{d} \ln E$ being positive
} 
equations are reestimated with $v^{*}$ based on the 0.116 stationary equilibrium value, the adjusted $R^{2}$ for supply drops to 0.39 , providing further support for the trending equilibrium calculation.

The impact on vacancies from a positive employment shock is effectively zero at a vacancy rate of one percent, but rises (in absolute value) to -0.43 (the same as the coefficient on the negative shock) at a vacancy rate of 5.9 percent and to -1.79 at a vacancy rate of 20 percent. Moreover, in the absence of employment growth, a high vacancy rate does not cause the vacancy rate to decline. The response to the gap between equilibrium and actual rent is also substantially smaller than in the basic model, 0.04 instead of 0.06 .

The impact on rental adjustment of partitioning employment changes into positive and negative values is similar in some respects. The interactive term is statistically and economically significant, indicating that the response to increases in employment is trivial at low vacancy rates (zero at a vacancy rate of one percent), but rises sharply at higher vacancy rates. It may seem puzzling that the cross effect between vacancies and positive employment change is positive. Note, however, that the response to the vacancy rate gap (at zero employment growth) is 75 percent higher in absolute value than in the basic model. Low vacancy rates trigger a 20 percent greater increase in rent in the asymmetric model than in the basic model when employment is growing at its 3.3 percent trend rate.

In the supply equation, cash flows above and below normal have significantly different impacts. Above normal cash flows $\left(v<v^{*}\right.$ and $\left.R>R^{*}\right)$ have a significantly positive effect on construction, whereas the impact of cash flows below normal level is essentially zero. The estimated impact of above normal cash flows is nearly triple that obtained in the basic model estimation.

To illustrate the improved fit of the asymmetric model, we simulate both models dynamically. We start with the observed values of $R, v, S$ and $E$ in 1977 and compute the changes between 1977 and 1978 using current actual changes in $E$ and lagged actual values of $R, v$ and $S$ for 1977 (and 1976 for $R$ ) as well as the lagged (1977) value of $R^{*}$ obtained by solving the long-run relationship using 1977 values of $S$ and $E$. For 1979 and later years we use the simulated 1978 values of $R, v$ and $S$, not the actual values. And so on through 2002.

The actual and predicted (based on the basic and asymmetric models) values of $R$ and $v$, respectively, are plotted in Figures 6 and 7. The models track the broad patterns in real rent and vacancies reasonably well. In particular they capture the turning points of the cycle in the late 1980s and early 1990s. However, the basic model substantially underpredicts the volatility of the cycle. Looking at real rents, nearly half of the sharp 50 percent rise from 1985 to 1990 is missed and the same for the sharp reversal in 1991-93. The predicted rent level is back on track in 1995 and following years until both 
models fail to capture the 2002 rent decline. Turning to the vacancy rate, both models overpredict vacancies during the 1980s but get the timing of the surge in vacancies peaking at 22 percent in 1994 and the subsequent reversal right. Again, however, the basic model explains only about half of the magnitude. The predictions based on asymmetric responses are substantially better, explaining fully 90 percent of the 50 percent rise in real rents between 1985 and 1990 and 75 percent of the surge in vacancies between 1989 and 1993. This illustrates the importance of allowing the nonlinear, asymmetric response to employment shocks. Both models miss the 2001-02 jump in vacancies.

The asymmetric model implies different adjustment paths for positive and negative shocks. Starting from $v=v^{*}$ the initial impact on $v$ and $R$ of an employment increase beyond trend is larger than that of a decrease in employment. Evaluated at $v^{*}$, the derivative of $\operatorname{dln} R$ is 1.97 with respect to $\operatorname{dln} E(+)$ and 1.44 with respect to $\mathrm{d} \ln E(-)$. The corresponding derivatives of $\mathrm{d} v$ are -0.53 and -0.43 , respectively. After three years the adjustment paths will also differ because the supply response is stronger for a positive than for a negative shock. Further, the adjustment path will differ markedly if the shock occurs when the market is out of equilibrium owing to the dependency of $\operatorname{dn} R$ and $\operatorname{dln} v$ on the level of $v$.

Simulating the adjustment is complicated, however, due to the non-linear nature of the model. The natural way to present a dynamic simulation is as the expected path conditional on an initial shock from a steady-state situation. With a linear model this can be computed as in Figures 6 and 7 as a deterministic simulation where all future disturbance terms are set equal to zero (the expected value). With our asymmetric model this no longer works and the expected path has to be calculated numerically across a large number of stochastic simulations. We leave this for future work.

Another interesting issue for the future is to analyze in more detail the nature of the adjustment path. Wheaton (1999) distinguishes between two types of cyclicality in response to shocks: overshooting relative to the new equilibrium and repeated oscillations around it. Our model simulation displays significant overshooting in response to an employment shock but only very small oscillations. An asymmetric model should be offer a richer menu of possible adjustment paths.

\section{Conclusion}

We draw a distinction between long run (or normal) demand for space, depending on the real rent on newly-written leases and a demand driver only, and short run demand or observed space occupancy, which depends not only on the current rent but on that when all existing leases were written. Space consumption may be locked in by long-term contracts in conjunction with transaction costs and restrictions on the breach of contracts. If most space had been leased under long-term contracts at earlier low rental rates, then current space consumption would be higher than if all space were being leased at 
today's high current rents. We refer to this excess space consumption as hidden vacancies, vacancies that may become open vacancies in the future when leases roll over if market rent remains at its current level. We show that a narrow measure of hidden vacancies computed as the difference in demands based on current and average rent tracks our broader measure of hidden vacancies fairly well, but far from perfectly.

Our model indicates that a sudden increase in space demand is initially met by a sharp decrease in vacancies, as well as a modest increase in rents (and the creation of hidden vacancies). In the intermediate run, rents rise farther to choke off demand, and the vacancy decline is reversed. Because many space users have longer term leases and thus do not immediately face the higher rent, rents overshoot the rise in equilibrium rent to restrict that limited portion of demand facing the higher lease rate. Eventually, of course, new supply comes on line and existing leases roll over at the higher rent, both of which act to reverse the rent increase.

The model converges to an equilibrium growth rate in real rents and a constant ("natural") vacancy rate. Thus, we compute the natural vacancy rate based on such a trending equilibrium. This yields a far more plausible estimate of 7.1 percent than the customary computation, which assumes a stationary equilibrium where real rent is constant and yields an implausibly high 11.6 percent estimate. Researchers need to consider the nature of the equilibrium carefully in this and other contexts.

Given the important role of long-term contracts in understanding hidden vacancies one would expect the whole dynamics of the process to depend on fraction of all contracts that is written each year. Future research should investigate this hypothesis more fully on alternative data sets. 


\section{References}

Arnott, R. (1989), "Housing Vacancies, Thin Markets and Idiosyncratic Tastes", Journal of Real Estate Finance and Economics 2, 5-30.

Englund, P., M. Hoesli, Å. Gunnelin and B. Söderberg (2004), "Implicit Forward Rents as Predictors of Future Rents", Real Estate Economics 32, 183-216.

Gardiner, C. and J. Henneberry (1988), "The Development of a Simple Regional Office Rent Prediction Model", Journal of Valuation 7, 36-52.

Gardiner, C. and J. Henneberry (1991), "Predicting Regional Office Rents Using Habit-persistence Theories", Journal of Property Valuation and Investment 9, 215-226.

Gunnelin, Å. and B. Söderberg (2003), "Term Structures in the Office Rental Market in Stockholm”, Journal of Real Estate Finance and Economics 26, 237-261.

Grenadier, S. R. (1995a), "Local and National Determinants of Office Vacancies”, Journal of Urban Economics 37, 57-71.

Grenadier, S. R. (1995b), “The Persistence of Real Estate Cycles”, Journal of Real Estate Finance and Economics 10, 95-119.

Grenadier, S. R. (1996), “The Strategic Exercise of Options: Development Cascades and Overbuilding in Real Estate Markets”, Journal of Finance 51, 1653-1679.

Hendershott, P. H. (1996), "Rental Adjustment and Valuation in Overbuilt Markets: Evidence from Sydney”, Journal of Urban Economics 39, 51-67.

Hendershott, P. H., C. M. Lizieri, and G. A. Matysiak (1999), “The Workings of the London Office Market", Real Estate Economics 27, 365-387.

Hendershott, P. H., B. D. MacGregor, and R. Tse (2002), "Estimation of the Rental Adjustment Process", Real Estate Economics 30, 165-183.

Hendershott, P. H., B. D. MacGregor, and M. White (2002), "Explaining Real Commercial Rents Using an Error-Correction Model with Panel Data", Journal of Real Estate Finance and Economics 24, 59-88.

Smith, L. B. (1974), “A Note on the Rent Adjustment Mechanism for Rental Housing," American Economic Review 64, 478-81.

Silver, M. and M. Goode (1990), "Econometric Forecasting Model for Rents in the British Retail Property Market," International Journal of Management Sciences 18, 529-539.

Voith, R. and T. Crone (1988), "National Vacancy Rates and the Persistance of Shocks in U.S. Office Markets", AREUEA Journal 16, 437-458.

Webb, R. B. and J. D. Fisher (1996), "Development of an Effective Rent (Lease) Index for the Chicago CBD”, Journal of Urban Economics 39, 1-19. 
Wheaton, W.C. (1990), "Vacancy, Search and Prices in a Housing Market Matching Model”, Journal of Political Economy 98, 1270-1293.

Wheaton, W.C. (1999), “Real Estate 'Cycles’: Some Fundamentals”, Real Estate Economics 27, 209-230.

Wheaton, W.C. and R. G. Torto (1994), "Office Rent Indices and their Behavior over Time", Journal of Urban Economics 35, 121-139.

Wheaton, W.C., R. G. Torto and P. Evans (1997), "The Cyclic Behavior of the Greater London Office Market”, Journal of Real Estate Finance and Economics 15, 77-92. 
Table 1. Number of leases. number of properties. average lease length. and fraction of new contracts.

\begin{tabular}{|c|c|c|c|c|}
\hline Year & $\begin{array}{c}\text { Number of } \\
\text { leases }\end{array}$ & $\begin{array}{l}\text { Number of } \\
\text { properties }\end{array}$ & $\begin{array}{l}\text { Average lease } \\
\text { length (months) }\end{array}$ & $\begin{array}{c}\text { Fraction new } \\
\text { contracts }\end{array}$ \\
\hline 1972 & 59 & 16 & 14.2 & 1.00 \\
\hline 1973 & 18 & 12 & 17.6 & 1.00 \\
\hline 1974 & 24 & 10 & 16.3 & 0.67 \\
\hline 1975 & 31 & 13 & 12.8 & 0.78 \\
\hline 1976 & 35 & 19 & 25.5 & 0.74 \\
\hline 1977 & 74 & 16 & 17.6 & 0.75 \\
\hline 1978 & 43 & 16 & 15.3 & 0.75 \\
\hline 1979 & 60 & 14 & 20.2 & 0.75 \\
\hline 1980 & 57 & 22 & 18.8 & 0.55 \\
\hline 1981 & 77 & 23 & 22.1 & 0.52 \\
\hline 1982 & 64 & 21 & 27.6 & 0.58 \\
\hline 1983 & 71 & 20 & 29.5 & 0.55 \\
\hline 1984 & 56 & 20 & 28.3 & 0.45 \\
\hline 1985 & 45 & 18 & 37.6 & 0.42 \\
\hline 1986 & 48 & 23 & 29.8 & 0.48 \\
\hline 1987 & 73 & 35 & 40.9 & 0.44 \\
\hline 1988 & 112 & 33 & 31.9 & 0.45 \\
\hline 1989 & 149 & 36 & 39.4 & 0.42 \\
\hline 1990 & 105 & 40 & 39.1 & 0.35 \\
\hline 1991 & 61 & 36 & 35.7 & 0.34 \\
\hline 1992 & 87 & 41 & 36.2 & 0.40 \\
\hline 1993 & 96 & 37 & 39.4 & 0.37 \\
\hline 1994 & 105 & 31 & 40.8 & 0.36 \\
\hline 1995 & 69 & 29 & 39.8 & 0.37 \\
\hline 1996 & 62 & 26 & 37.5 & 0.37 \\
\hline 1997 & 58 & 39 & 38.1 & 0.37 \\
\hline 1998 & 68 & 63 & 37.9 & 0.37 \\
\hline 1999 & 183 & 79 & 40.3 & 0.30 \\
\hline 2000 & 198 & 73 & 39.2 & 0.36 \\
\hline 2001 & 181 & 64 & 37.8 & 0.33 \\
\hline 2002 & 116 & 41 & 36.3 & 0.32 \\
\hline Total & 2.485 & & & \\
\hline
\end{tabular}

Note: Number of leases refers to the number of contracts in our data base first effective in a certain year. Number of properties refers to properties where the offices covered by those leases are located. Average lease length refers to the unweighted average across these contracts. Fraction new contracts is calculated as described in the text. 
Table 2. Definition of variables in the rent index regression and descriptives for 1972-2002.

\begin{tabular}{|c|c|c|c|}
\hline Variable & Definition & Mean & Std. dev. \\
\hline Rent & Rent per square meter (per year). real (in 1992 SEK). & 2.046 .0 & 1.338 .7 \\
\hline Size & $\begin{array}{l}\text { Total rental space per lease unit (in thousand square } \\
\text { meters). }\end{array}$ & 0.2964 & 0.3797 \\
\hline Age & $\begin{array}{l}\text { Effective age of the building. in the year when the lease } \\
\text { contract was written. as estimated by the assessment } \\
\text { authority taking renovations into account (in years). }\end{array}$ & 41.9 & 20.1 \\
\hline Renego & $\begin{array}{l}\text { Dummy }=1 \text { if contract is the result of renegotiations with } \\
\text { the previous tenant. }\end{array}$ & 0.436 & - \\
\hline$C P I$ & $\begin{array}{l}\text { Percentage of rent that is indexed to the Consumer Price } \\
\text { Index. }\end{array}$ & 0.799 & 0.377 \\
\hline Term & Length of the rental period (in months). & 33.53 & 16.40 \\
\hline Heat_l & $\begin{array}{l}\text { Dummy for heating clause }=1 \text { for leases where the tenant } \\
\text { provides and pays for heating. (1998-2002 only). }\end{array}$ & 0.0056 & - \\
\hline Heat_2 & $\begin{array}{l}\text { Dummy for heating clause }=1 \text { for leases where base rent } \\
\text { is net of heating expenses. which are charged separately } \\
\text { (1998-2002 only). }\end{array}$ & 0.0640 & - \\
\hline Heat_3 & $\begin{array}{l}\text { Dummy for heating clause }=1 \text { for leases where type of } \\
\text { heating clause is unknown (1998-2002 only). }\end{array}$ & 0.0241 & - \\
\hline Concession & $\begin{array}{l}\text { Dummy }=1 \text { for concessions and graduated rent for leases } \\
1992-2002 \text { (only); otherwise }=0 . \text { (Rents for leases } 1972- \\
1991 \text { are transformed to effective rents). }\end{array}$ & 0.0716 & - \\
\hline Unknown_esc & $\begin{array}{l}\text { Dummy }=1 \text { if lease escalation clause exists. but the exact } \\
\text { escalation is unknown (1998-2002 only). }\end{array}$ & 0.0314 & - \\
\hline Prop_tax & $\begin{array}{l}\text { Dummy }=1 \text { if base rent is net of property tax (1992-1997 } \\
\text { only). }\end{array}$ & 0.1163 & - \\
\hline
\end{tabular}


Table 3. OLS estimates of the hedonic rent index model for 1972-2002.

Dependent variable is $\ln$ Rent.

\begin{tabular}{|c|c|c|}
\hline & Coefficient & $t$-value \\
\hline Intercept & 5.0213 & 26.74 \\
\hline Heat_l & 0.0401 & 0.66 \\
\hline Heat_2 & 0.0909 & 3.18 \\
\hline Heat_3 & -0.0372 & -0.95 \\
\hline Prop_tax & -0.0196 & -0.86 \\
\hline Concession & -0.0192 & -1.10 \\
\hline Renego & -0.0468 & -5.01 \\
\hline Unknown_esc & 0.0747 & 2.26 \\
\hline CPI & 0.0529 & 3.22 \\
\hline Size & 0.1970 & 6.04 \\
\hline$S i z e^{2}$ & -0.0803 & -4.70 \\
\hline Adjusted $R^{2}$ & 0.962 & \\
\hline \multicolumn{3}{|c|}{$\begin{array}{l}\text { Note: The model includes year dummies. Term and Term squared interacted with year d } \\
\text { dummies. Age was (close to being) a linear combination of other variables and thus excl }\end{array}$} \\
\hline \multicolumn{3}{|c|}{$\begin{array}{l}\text { Table } 4 \text {. OLS estimates of cointegrating equation. 1977-2002. Dependent } \\
\text { variable is } \ln R \text {. }\end{array}$} \\
\hline & Coefficient & $t$-value \\
\hline Intercept & 13.499 & 1.40 \\
\hline $\ln S$ & -1.803 & -2.42 \\
\hline $\ln E$ & 1.880 & 9.08 \\
\hline Adjusted $R^{2}$ & 0.786 & \\
\hline
\end{tabular}


Table 5. Estimates of error correction models

\begin{tabular}{|c|c|c|c|c|}
\hline & \multicolumn{2}{|c|}{ Basic model } & \multicolumn{2}{|c|}{ Asymmetric model } \\
\hline & Coefficient & $t$-value & Coefficient & $t$-value \\
\hline \multicolumn{5}{|l|}{ Rent $(\mathrm{d} \ln R)$} \\
\hline Intercept & 0.1881 & 3.04 & 0.2977 & 3.99 \\
\hline $\mathrm{d} \ln R(t-1)$ & -0.3217 & -2.43 & -0.4435 & -3.12 \\
\hline $\mathrm{d} \ln R(t-2)$ & -0.3217 & -2.43 & -0.4435 & -3.12 \\
\hline $\mathrm{d} \ln S$ & -1.3783 & -0.72 & -1.6115 & -0.97 \\
\hline $\mathrm{d} \ln E$ & 1.2159 & 3.40 & & \\
\hline $\mathrm{d} \ln E(+)$ & & & -0.5358 & -0.82 \\
\hline $\mathrm{d} \ln E(-)$ & & & 1.4384 & 1.41 \\
\hline$v(t-1) \cdot \mathrm{d} \ln E(+)$ & & & 36.4285 & 2.95 \\
\hline$v(t-1)$ & -1.9742 & -3.48 & -3.5674 & -4.71 \\
\hline$d(t-1)$ & -0.3780 & -3.62 & -0.2873 & -3.09 \\
\hline Adjusted $R^{2}$ & 0.581 & & 0.670 & \\
\hline \multicolumn{5}{|l|}{ Vacancy rate $(\mathrm{d} v)$} \\
\hline Intercept & 0.0292 & 3.78 & 0.0120 & 1.74 \\
\hline $\mathrm{d} \ln S$ & -0.0809 & -0.22 & -0.2344 & -0.90 \\
\hline $\mathrm{d} \ln E$ & -0.3579 & -4.97 & & \\
\hline $\operatorname{d} \ln E(+)$ & & & 0.1368 & 1.23 \\
\hline $\mathrm{d} \ln E(-)$ & & & -0.4341 & -2.56 \\
\hline$v(t-1) \cdot \mathrm{d} \ln E(+)$ & & & -9.6330 & -4.61 \\
\hline$v(t-1)$ & -0.2327 & -3.58 & 0.0716 & 0.89 \\
\hline$\varepsilon(t-1)$ & 0.0604 & 2.85 & 0.0418 & 2.73 \\
\hline Adjusted $R^{2}$ & 0.579 & & 0.770 & \\
\hline \multicolumn{5}{|l|}{ Supply $(\mathrm{d} \ln S)$} \\
\hline Intercept & 0.0146 & 6.40 & -0.0015 & -0.36 \\
\hline$v(t-3)$ & -0.0759 & -2.79 & & \\
\hline$\varepsilon(t-3)$ & 0.0236 & 2.71 & & \\
\hline$\left(v(t-3)-v(t-3)^{*}\right)(+)$ & & & 0.0110 & 0.23 \\
\hline$\left(v(t-3)-v(t-3)^{*}\right)(-)$ & & & -0.2179 & -2.45 \\
\hline$\varepsilon(t-3)(+)$ & & & 0.0618 & 3.84 \\
\hline$d(t-3)(-)$ & & & -0.0081 & -0.51 \\
\hline Adjusted $R^{2}$ & 0.322 & & 0.429 & \\
\hline \multicolumn{5}{|l|}{ Employment $(\mathrm{d} \ln E)$} \\
\hline Intercept & 0.0259 & 2.37 & & \\
\hline $\mathrm{d} \ln E(t-1)$ & 0.2147 & 1.01 & & \\
\hline Adjusted $R^{2}$ & 0.006 & & & \\
\hline \multicolumn{5}{|l|}{ Steady-state values } \\
\hline Natural vacancy & 0.0715 & & 0.0710 & \\
\hline $\mathrm{d} \ln R$ trend & 0.0452 & & 0.0452 & \\
\hline $\mathrm{d} \ln S$ trend & 0.0092 & & 0.0099 & \\
\hline $\mathrm{d} \ln E$ trend & 0.0330 & & 0.0330 & \\
\hline
\end{tabular}

The model equations are estimated by seemingly unrelated regression. The employment equation is estimated by OLS. 
Figure 1. Real rent in Stockholm 1972-2002 (SEK per square meter, 1992 price level) on new leases and average rent across all leases.

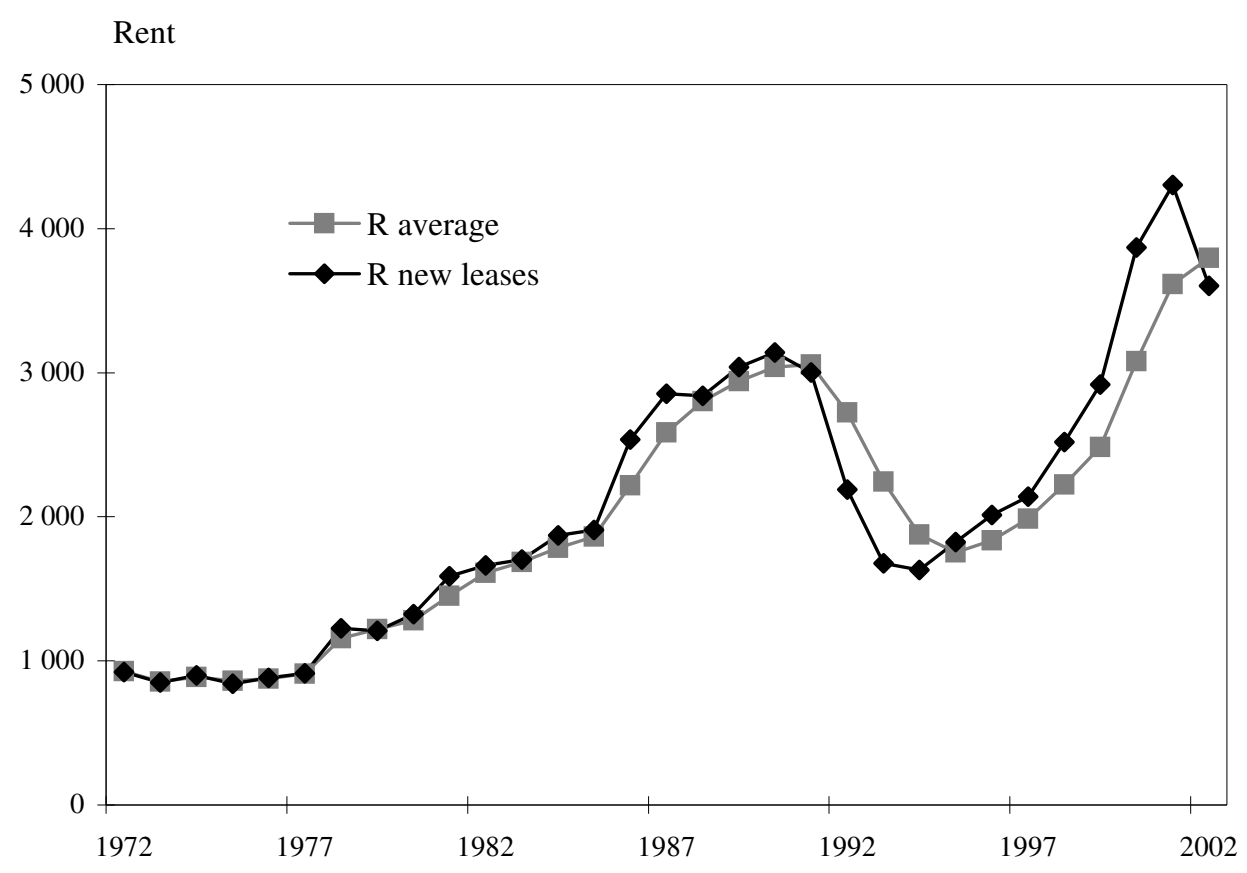


Figure 2. Real rent (new leases), vacancy rate, supply of office space and employment in service industries, Stockholm 1972-2002.
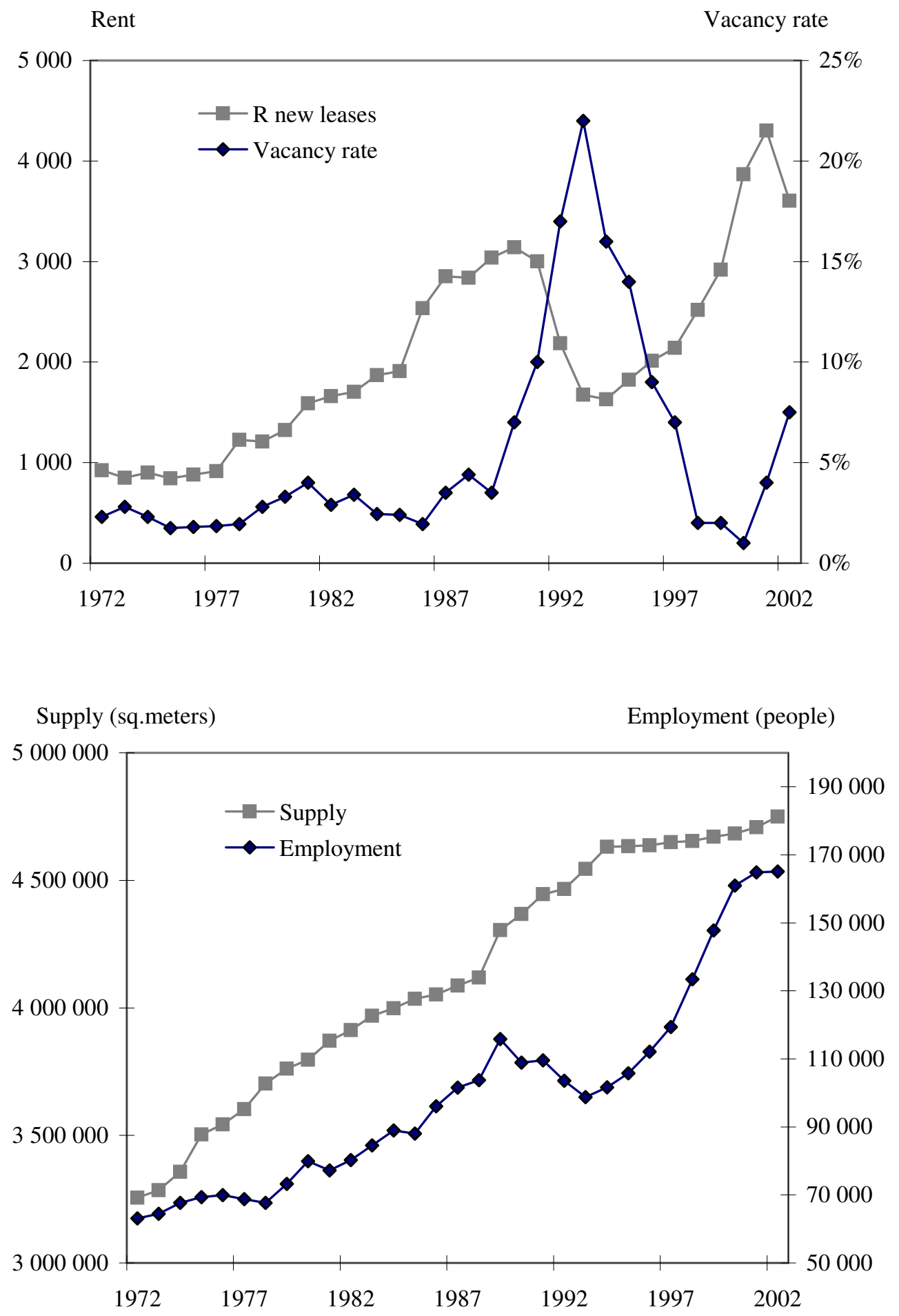
Figure 3. Real rent for new leases and estimated equilibrium rent $\left(R^{*}\right), 1977-2002$.

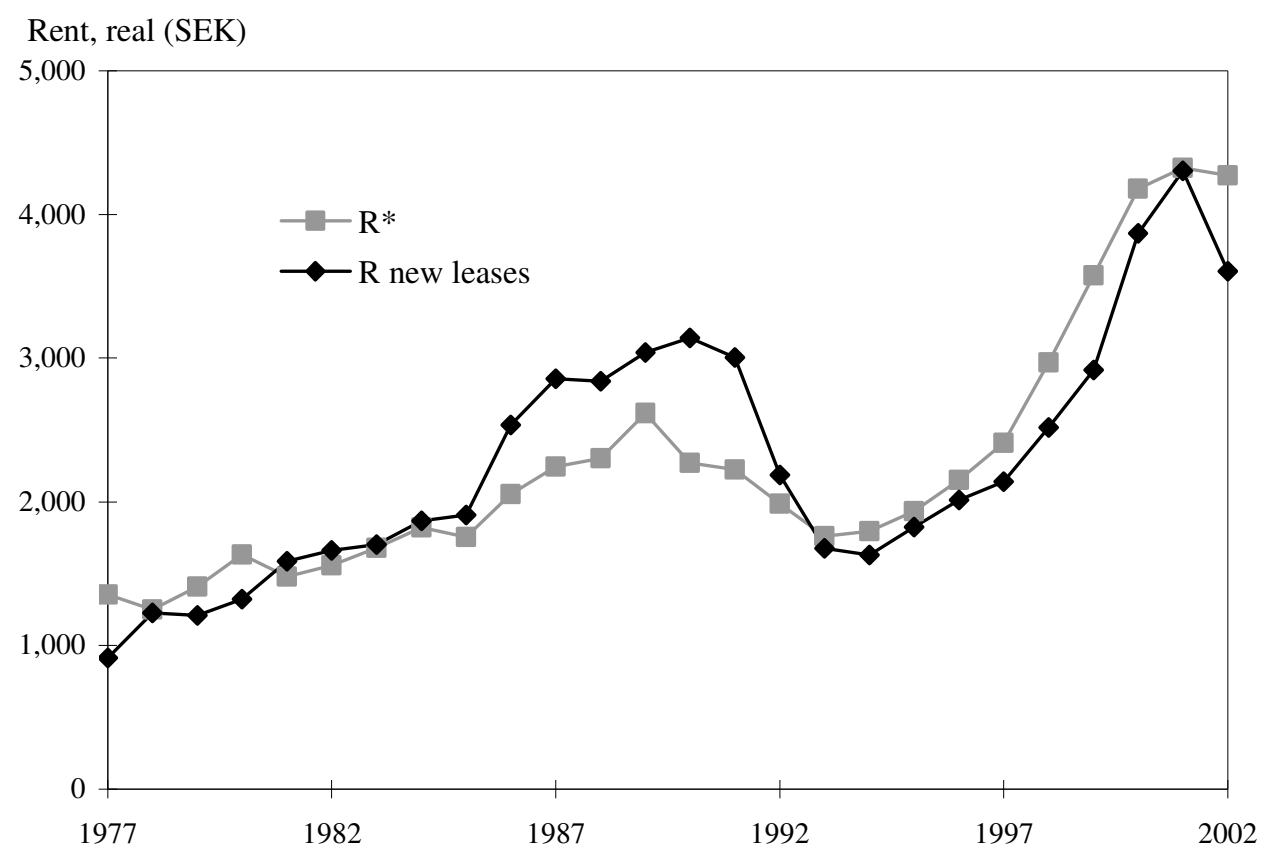

Figure 4. Two measures of hidden vacancies, basic model.

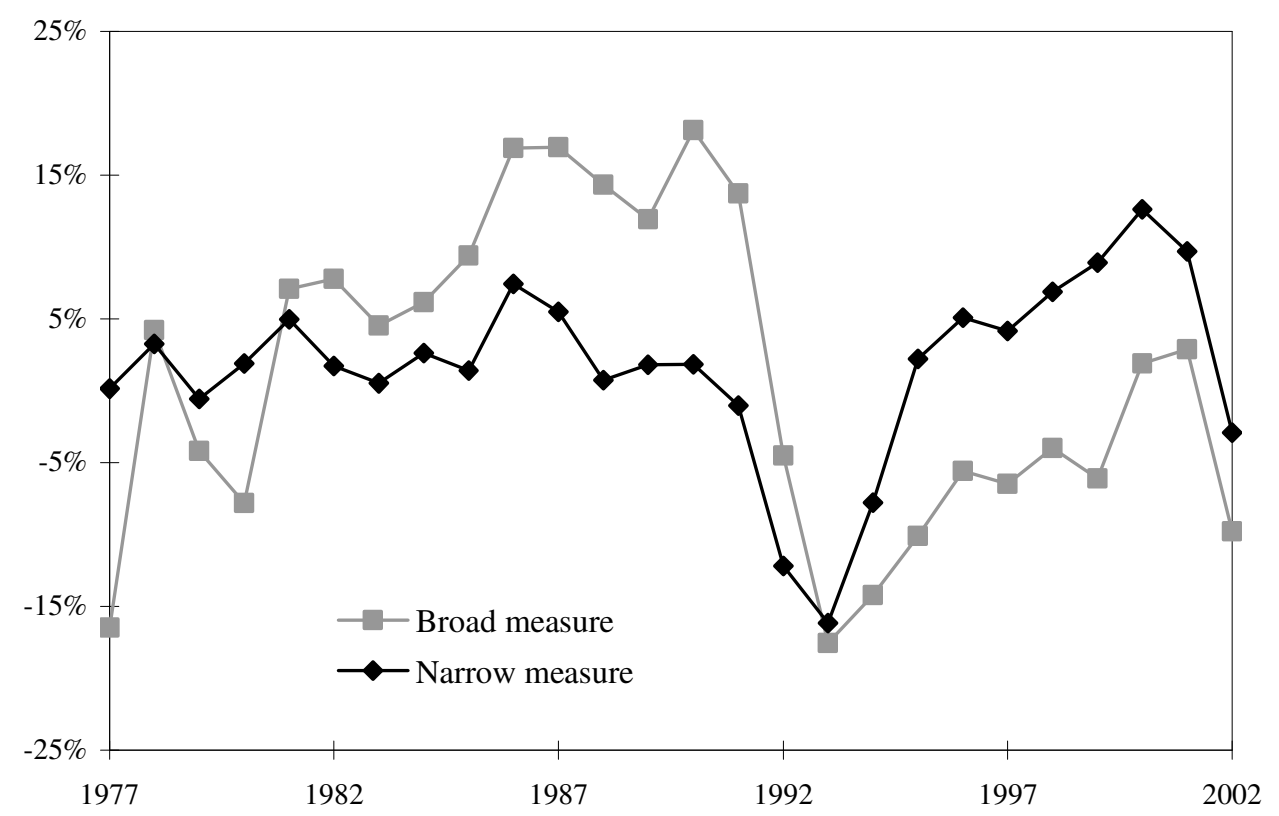


Figure 5. Simulated impact on rent, supply, and vacancies of a permanent 10 percent employment increase in addition to trend, basic model.
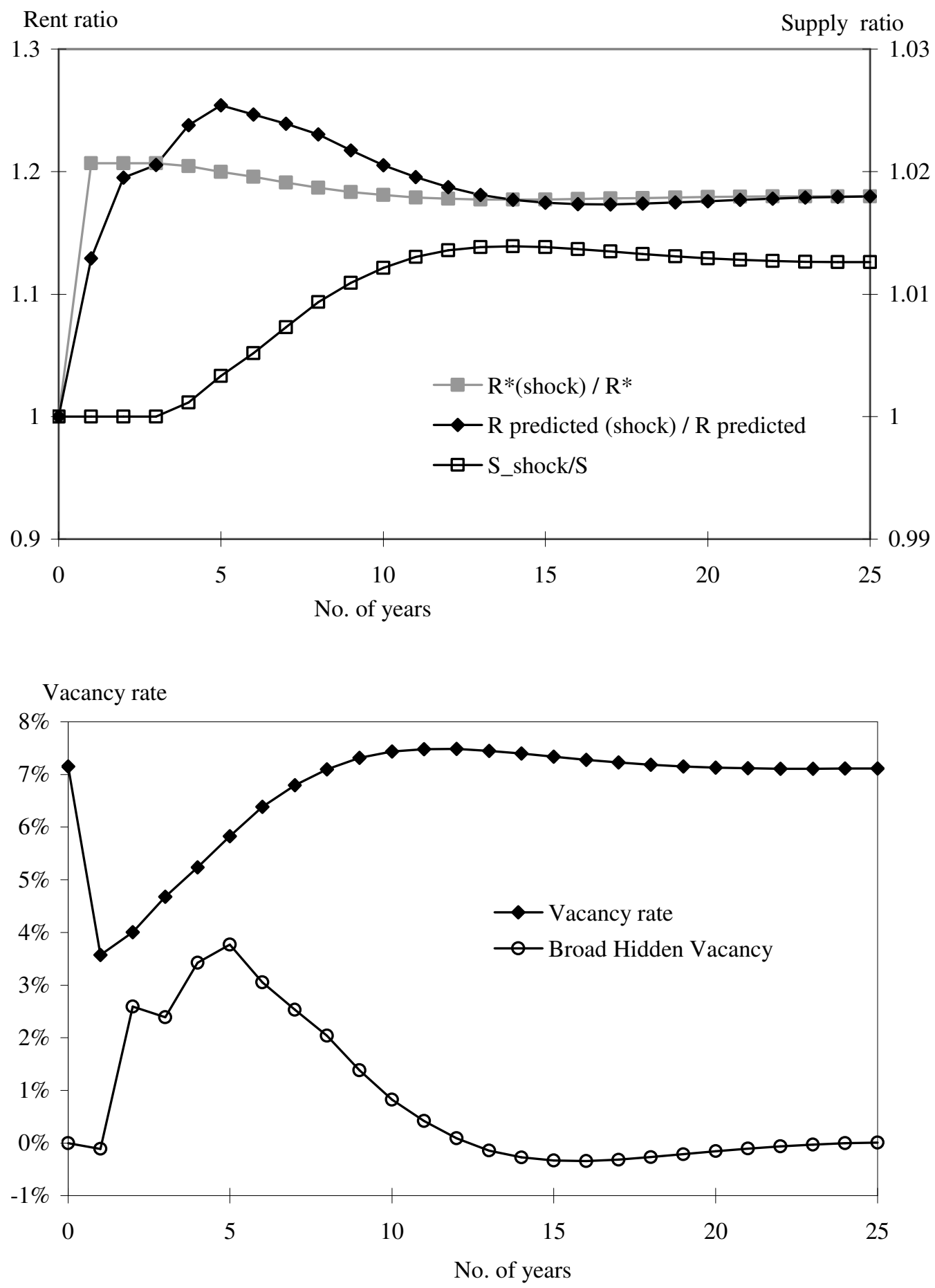
Figure 6. Real rent for new leases and predicted rent based on basic model and asymmetric model, 1977-2002.

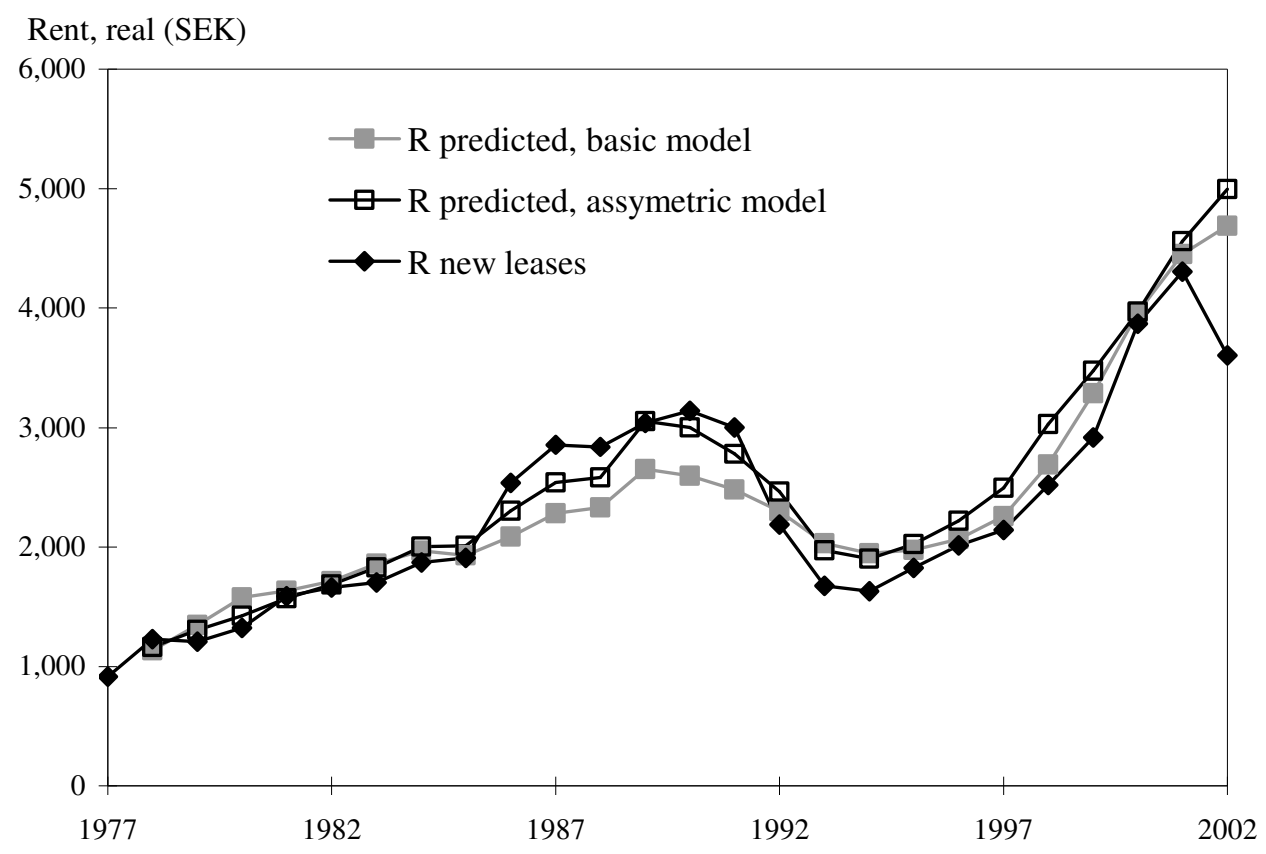

Figure 7. Actual vacancy rate and predicted vacancy based on basic model and asymmetric model, 1977-2002.

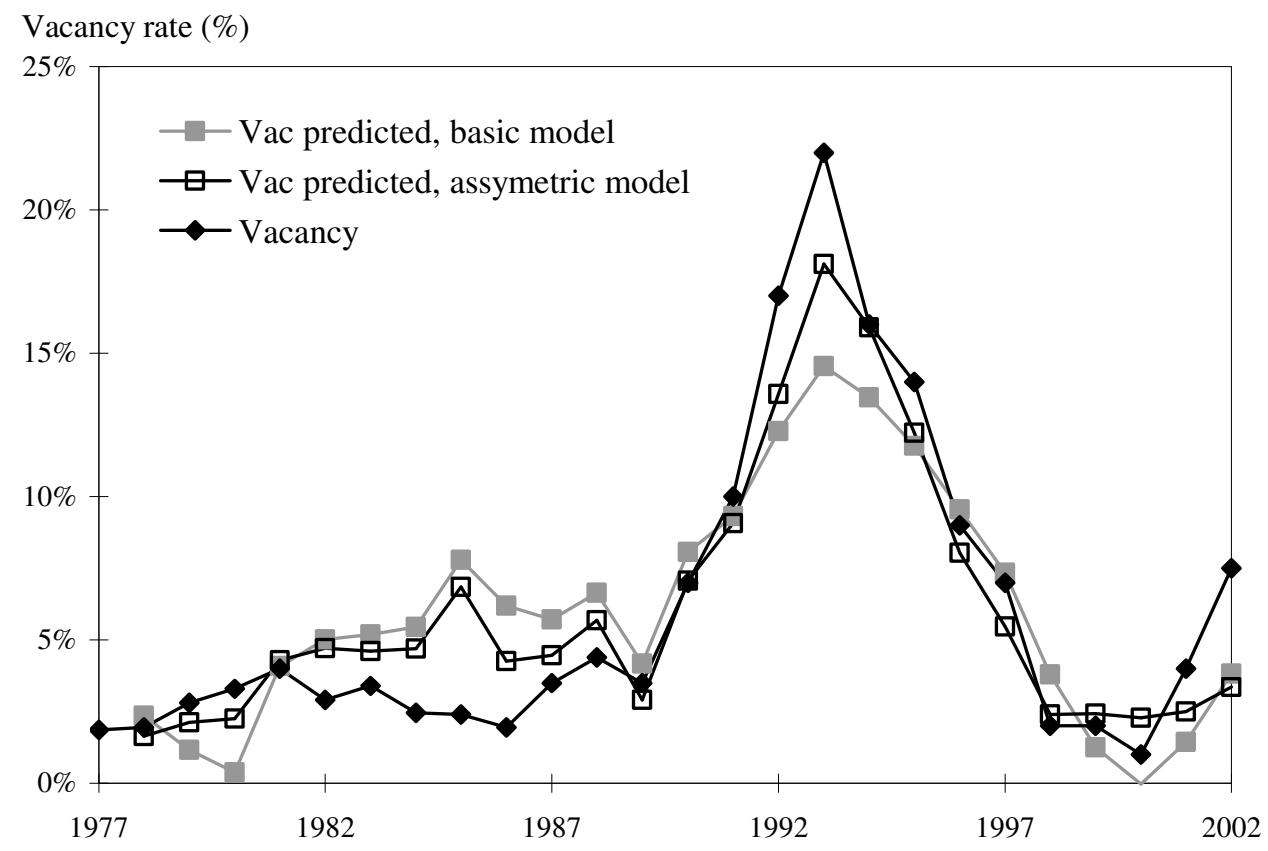


APPENDIX: TESTS FOR UNIT ROOTS. STATIONARITY AND COINTEGRATION.

Unit root and stationarity tests, 1977-2002 data

\begin{tabular}{ccccccc}
\hline & \multicolumn{2}{c}{ ADF } & \multicolumn{2}{c}{ PP } & \multicolumn{2}{c}{ KPSS } \\
Variable & test statistic & prob.value & Test statistic & prob.value & test statistic & prob.value \\
\hline & & & & & & \\
$\ln R$ & -2.49 & 0.33 & -1.92 & 0.61 & 0.102 & $>0.10$ \\
$\ln E$ & -3.54 & 0.06 & -1.80 & 0.68 & 0.085 & $>0.10$ \\
$\ln S$ & -0.90 & 0.94 & -1.08 & 0.91 & 0.147 & $<0.05$ \\
$v a c$ & -3.52 & 0.06 & -1.83 & 0.66 & 0.104 & $>0.10$
\end{tabular}

ADF: Augmented Dickey-Fuller unit root test. Null hypothesis: unit root. Intercept and trend in test equation. Automatic selection of no. of lags (maximum=3). MacKinnon (1996) one-sided p-values.

PP: Phillips-Perron unit root test. Null hypothesis: unit root. Intercept and trend in test equation. Automatic selection of bandwidth. MacKinnon (1996) one-sided p-values.

KPPS: Kwiatkowski-Phillips-Schmidt-Shin (1992) test. Null hypothesis: stationarity. Intercept and trend in test equation. Automatic selection of bandwidth. Critical values at the $5 \%$ and $10 \%$ levels are 0.146 and 0.119 , respectively.

Cointegration test for $\ln R, \ln E$ and $\ln S, 1977-2002$ data

\begin{tabular}{lcc}
\hline No. of cointegrating vectors & Johansen test statistic & Prob. value \\
\hline None & 46.06 & 0.0023 \\
At most 1 & 14.66 & 0.1545 \\
At most 2 & 3.77 & 0.0522
\end{tabular}

Johansen unrestricted rank test allowing for quadratic deterministic trend. Intercept and three lags of differenced variables in test equation. MacKinnon-Haug-Michelis (1999) p-values. 